\title{
GCU
}

Glasgow Caledonian

University

University for the Common Good

\section{Efficiency of internal curing by superabsorbent polymers (SAP) in PC-GGBS mortars} Almeida, Fernando G. ; Klemm, Agnieszka J.

Published in:

Cement and Concrete Composites

DOI:

10.1016/j.cemconcomp.2018.01.002

Publication date:

2018

Document Version

Author accepted manuscript

Link to publication in ResearchOnline

Citation for published version (Harvard):

Almeida, FG \& Klemm, AJ 2018, 'Efficiency of internal curing by superabsorbent polymers (SAP) in PC-GGBS mortars', Cement and Concrete Composites, vol. 88, pp. 41-51.

https://doi.org/10.1016/j.cemconcomp.2018.01.002

\section{General rights}

Copyright and moral rights for the publications made accessible in the public portal are retained by the authors and/or other copyright owners and it is a condition of accessing publications that users recognise and abide by the legal requirements associated with these rights.

Take down policy

If you believe that this document breaches copyright please view our takedown policy at https://edshare.gcu.ac.uk/id/eprint/5179 for details of how to contact us. 


\title{
Efficiency of internal curing by superabsorbent polymers (SAP) in PC-GGBS mortars
}

\author{
Fernando C.R. Almeida ${ }^{1, a}$ and Agnieszka J. Klemm ${ }^{1, b}$ \\ ${ }^{1}$ Glasgow Caledonian University, School of Engineering and Built Environment, \\ Cowcaddens Road, Glasgow G4 0BA, UK

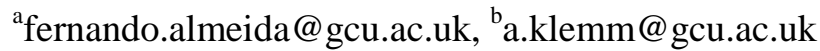

\begin{abstract}
This paper evaluates the effect of superabsorbent polymers (SAP) on hydration and microstructure of PC-GGBS mortars. Development of autogenous shrinkage, microstructural characteristics (MIP/SEM) and compressive strength were analysed during the first 90 days. Four levels of Portland cement (PC) replacement by GGBS $(0 \%, 25 \%, 50 \%$ and $75 \%)$ and two types of SAP with different water absorption capacities were considered. The results proved the efficiency of internal curing by SAPs in PC-GGBS systems due to significant reduction in autogenous shrinkage, especially for higher contents of GGBS. SAP facilitates GGBS hydration activated by portlandite; its products can be deposited into the nano pores leading to a small relative expansion of the hardened bulk volume. This process is initiated during the second week and it lasts until the sixth week. Despite increased total porosity, compressive strength of SAPs modified mortars is comparable to the reference samples for low GGBS contents in advanced ages.
\end{abstract}

Keywords: Superabsorbent polymers (SAP), ground granulated blast-furnace slag (GGBS), mortars, autogenous shrinkage, microstructure.

\section{Highlights:}

- The higher GGBS content the higher is reduction in autogenous shrinkage by SAPs;

- Precipitation of CSH (from GGBS hydration) is additionally facilitated by the availability of water-filled space provided by collapsed SAPs;

- GGBS hydrated products deposited in pores below $20 \mathrm{~nm}$ may lead to a small relative expansion of mortar up to the end of the sixth week;

- SAP does not affect compressive strength for GGBS contents up to $50 \%$ and without additional water at 90 days.

\section{Graphical Abstract.}

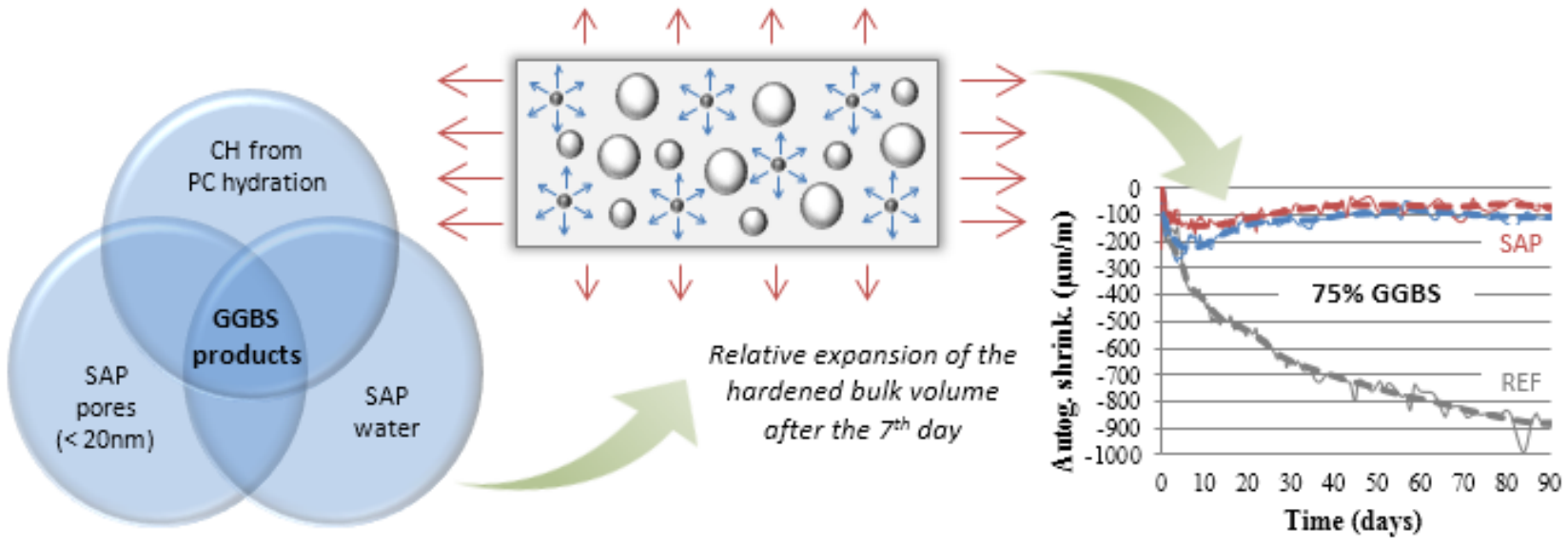




\section{Introduction}

The main constituents of Portland cement (PC) responsible for gain of strength over time are reactive calcium silicates. Hydration of alite $\left(\mathrm{C}_{3} \mathrm{~S}\right)$ and belite $\left(\beta \mathrm{C}_{2} \mathrm{~S}\right)$ produce mainly calcium silicate hydrates $(\mathrm{CSH})$ and calcium hydroxide $(\mathrm{CH})($ Eqs. 1-2).

$$
\begin{gathered}
\text { Alite: } \quad 2 C_{3} S+11 H \rightarrow C_{3} S_{2} H_{8}+3 C H \\
\text { Belite: } \quad 2 C_{2} S+9 H \rightarrow C_{3} S_{2} H_{8}+C H
\end{gathered}
$$

In cementitious materials, $\mathrm{CSH}$ is primarily responsible for its adhesive characteristic, creating a rigid, dense and stable skeleton. Additionally, $\mathrm{CH}$ can increase alkalinity and also improve densification of the interfacial transition zone. Thermodynamic modelling shows that more and more $\mathrm{CSH}$ and $\mathrm{CH}$ are formed with time until a certain level of saturation is reached. For portlandite, it is about $1000 \mathrm{~h}$ after beginning of hydration (Fig. 1) [1]. Alteration in solid phases during PC hydration implies a decreased pore solution and formation of microstructure which determines hardened properties of concrete.

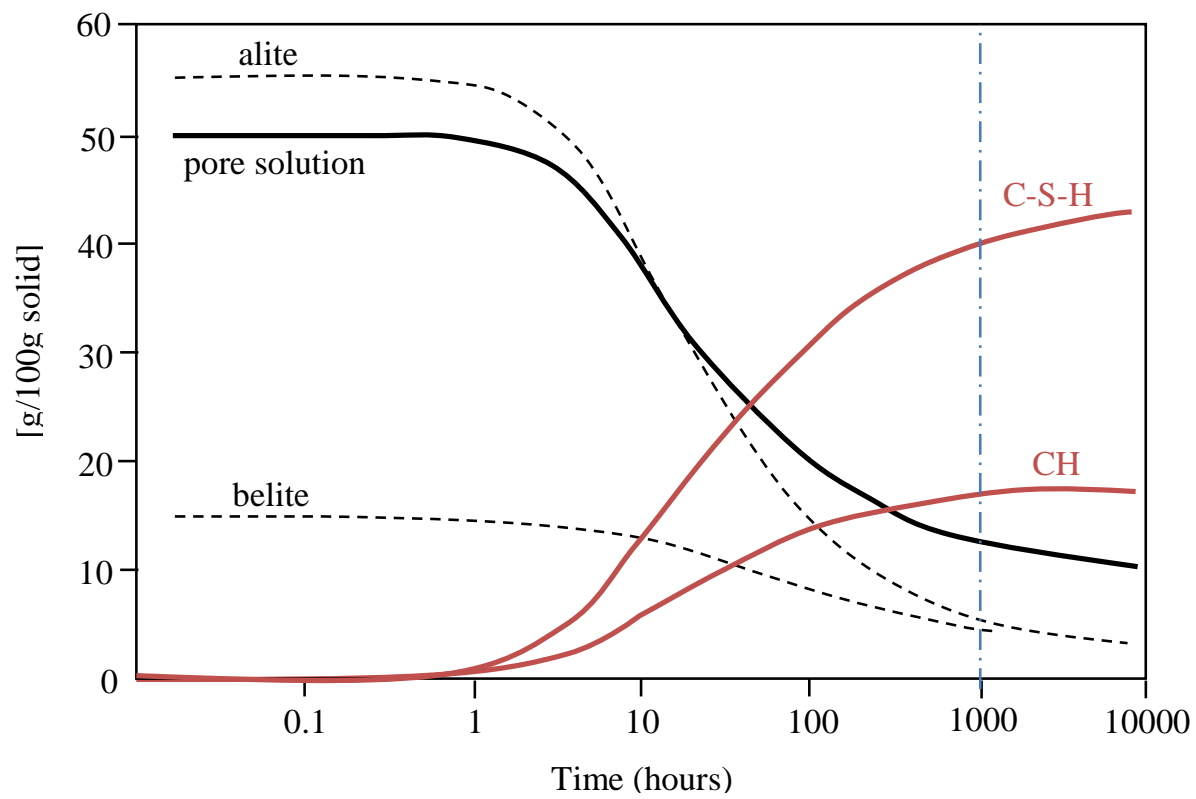

Fig. 1. Evolution of the main solid phases during the hydration of Portland cement (adapted from [1]).

However, the rate and extend of reactions can be influenced by the presence of supplementary cementitious materials, such as ground granulated blast-furnace slag (GGBS) [2,3]. GGBS reaction is slower than the reaction of clinker phases, and depends on the chemical composition, fineness, glass content as well as on the composition of interacting solution [3]. The presence of GGBS slightly reduces alkali concentration (due to lower potassium and sodium contents) and $\mathrm{pH}$-values (due to lower $\mathrm{OH}^{-}$contents) of the blended system. Sulphur species negatively charged, such as sulphide, sulphite and thiosulfate, can additionally decrease $\mathrm{OH}^{-}$concentration of the pore solution $[1,4,5]$.

GGBS presents primarily cementitious behaviour (latent hydraulic activity) but it may also show some minimal pozzolanic features (reaction with $\mathrm{CH}$ ) [6-8]. Reactivity of GGBS requires, however, an alkaline activator to raise $\mathrm{pH}$ in the vicinity of the slag. This is to prevent formation of a thin Si-rich layer on the surface of its grains (during GGBS hydration), which stifles further slag reactions. Thus, PC itself shows as a suitable activator in providing $\mathrm{CH}$ and alkali hydroxides $[9,10]$. Reactivity of slag increases when more PC is present in blended system due to increased $\mathrm{pH}$. Eqs. 3-4 show both GGBS reactions, where $\mathrm{CH}$ plays an important role in producing further $\mathrm{CSH}$ in a presence of water. 


$$
\begin{gathered}
\text { Hydraulic reaction: } G G B S+\text { water } \stackrel{C H}{\rightarrow} C-S-H+\text { other phases } \\
\text { Pozzolanic reaction: } \quad G G B S+C H+\text { water } \rightarrow C-S-H
\end{gathered}
$$

Nevertheless, there is still no consensus on the mechanisms controlling hydration kinetics especially beyond one day. This is due to the difficulty to quantitatively measure GGBS reaction in blended systems [3]. It is well known that at early ages (up to 30 hours) "filler effects" dominate leading to an increased, and sometimes also faster, reaction of the PC phases. This is due to more space relative to the amount of clinker (dilution effect) and increased nucleation rates [2,3,11-13]. Due to smaller number of clinker grains in a blended system, there is relatively more space for formation of hydrates in early ages and hence the degree of clinker reaction is significantly higher (than in a plain material) [11]. Thus, higher early reaction rate in GGBS systems can reflects on higher chemical shrinkage trigged by self-desiccation process [2,3,14-18]. Additionally, GGBS can refine capillary pores in blended paste and lead to a higher tensile stress generated by the water menisci during hydration processes. Due to the surface tension of water, the force of attraction between pore walls increases as water is consumed, contributing to greater shrinkage $[14,18]$.

However after the first day, there are only speculations that the degree of GGBS reaction could be limited by lack of space filled by early PC hydrated products [2]. Hydration in long term regime is mainly due to $\mathrm{C}_{2} \mathrm{~S}$ (and perhaps ferrite) phases by the increment of the sheets number in the nanocrystalline regions of CSH [19]. In studies with GGBS matrices, Berodier \& Scrivener [20] showed that systems with w/s (water-to-solid) ratios of 0.6 and 0.4 have similar kinetics in the first week, indicating that space does not limit reaction during early ages. Then from the $7^{\text {th }}$ day, reaction slows down in the lower w/s system with less space, while it continues in the higher w/s system. This effect indicates that the slowdown of high content of slag reaction is a result of lack of space in later ages. Thus, there is a minimum critical pore entry radius reached at high degrees of hydration (around $8 \mathrm{~nm}$ ). Below that, formation of hydrates is restricted by the lack of water-filled capillary pores in later ages. Moreover, reaction of slag could suppress reaction of clinker phases, probably because of a competition for space. According to Scrivener et al [2], although there are no sufficient data on long term hydration to understand the mechanisms operating after 1 day, it is becoming clear that the amount of space available is a critical factor.

Superabsorbent polymers (SAP) have a potential application as internal curing agent for concrete and mortars. Its high capacity to absorb water from fresh mix and release it over time can control autogenous shrinkage in early ages [21-28]. Additionally, when SAP collapses, it leaves behind pores that can significantly change microstructure of hardened concrete and eventually provide more room for later products deposition [29-33].

Although there are some studies related to application of SAP on PC-GGBS materials [34-38] its effects on long term hydration and their microstructure are still unclear and deficient. This paper, therefore, aims to characterize hydration development and evaluate microstructural alterations in mortars with different levels of GGBS content modified by two different types of SAPs. The analysis is carried out by relating results of autogenous shrinkage, MIP/SEM and compressive strength development during 90 days.

\section{Methodology}

Mortars with different mix proportions have been produced in the experimental programme; four levels of Portland cement (CEM I 52.5N) replacement by GGBS (0\%, 25\%, 50\% and 75\%) were adopted. Chemical analysis of CEM I [39] and GGBS [40] are presented in Table 1.

Table 1 - Chemical composition of CEM I and GGBS (\%).

\begin{tabular}{cccccccccc}
\hline & $\mathrm{SiO}_{2}$ & $\mathrm{Al}_{2} \mathrm{O}_{3}$ & $\mathrm{Fe}_{2} \mathrm{O}_{3}$ & $\mathrm{CaO}$ & $\mathrm{MgO}$ & $\mathrm{SO}_{3}$ & $\mathrm{Na}_{2} \mathrm{O}$ & $\mathrm{K}_{2} \mathrm{O}$ & LOI \\
\hline CEM I & 20.1 & 4.9 & 2.7 & 62.4 & 2.2 & 3.2 & 0.3 & 0.6 & 2.8 \\
\hline GGBS & 34.5 & 13.1 & 0.2 & 38.5 & 9.7 & 0.4 & 0.2 & 0.6 & 0.6 \\
\hline
\end{tabular}


Analysis of particle size distribution by using a Mastersizer laser diffractometer (air as dispersant) showed that GGBS comprises larger particles than CEM I (Fig. 2). While GGBS contained $90 \%$ of particles below $49.78 \pm 0.23 \mu \mathrm{m}$, CEM I had the same amount under $41.55 \pm 0.29$ $\mu \mathrm{m}$. The mean diameters of GGBS and CEM I are shown in Fig. 2; these values were obtained from volume distribution $(\mathrm{D}[4,3])$ and surface area distribution $(\mathrm{D}[3,2])$.

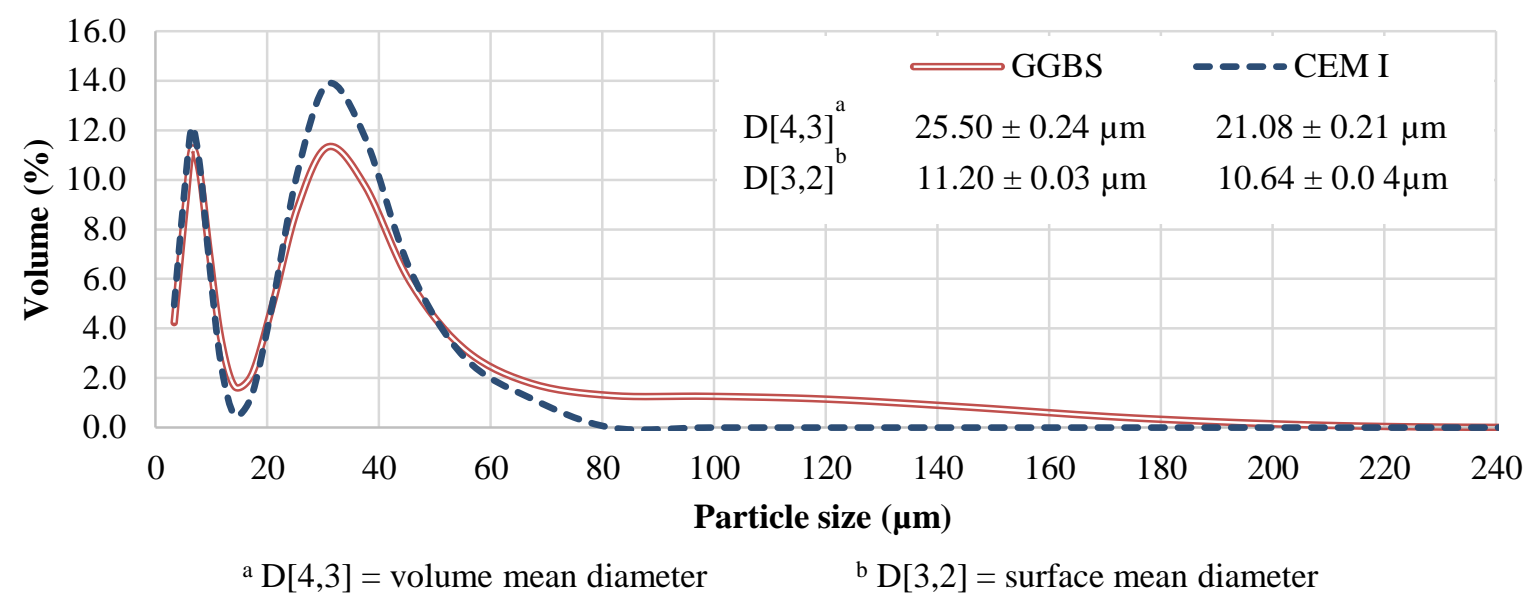

Fig. 2. Physical characterization of CEM I and GGBS.

Two types of modified polyacrylamide SAPs (provided by BASF Construction Chemicals $\mathrm{GmbH}$, Trostberg, Germany) have been used in the proportion of $0.25 \%$ by mass of binder. SAP X and SAP Y had maximum water absorption capacities (WAC) in cement filtrate solution $(\mathrm{w} / \mathrm{c}=5)$ of $39 \mathrm{~g} / \mathrm{g}$ and $47 \mathrm{~g} / \mathrm{g}$ respectively. They were measured by the tea-bag method up to $3 \mathrm{~h}$ (max WAC was obtained during the first 30min of testing for both SAPs) [25]. In mixing water, SAP X and SAP Y had WAC of $24 \mathrm{~g} / \mathrm{g}$ and $32 \mathrm{~g} / \mathrm{g}$, respectively. They were measured based on the amount of additional water required to obtain a flow value similar to a reference mortar with w/c ratio of 0.42 , i.e., $119 \pm 1 \mathrm{~mm}$ [41-43]. Fig. 3 shows SEM micrographs of both SAPs in dry conditions; they present predominant particles sizes in the range of 30-140 $\mu \mathrm{m}$ and mode values of $95.19 \pm 0.43 \mu \mathrm{m}$ and $85.74 \pm 0.23 \mu \mathrm{m}$ for SAP X and SAP Y, respectively.
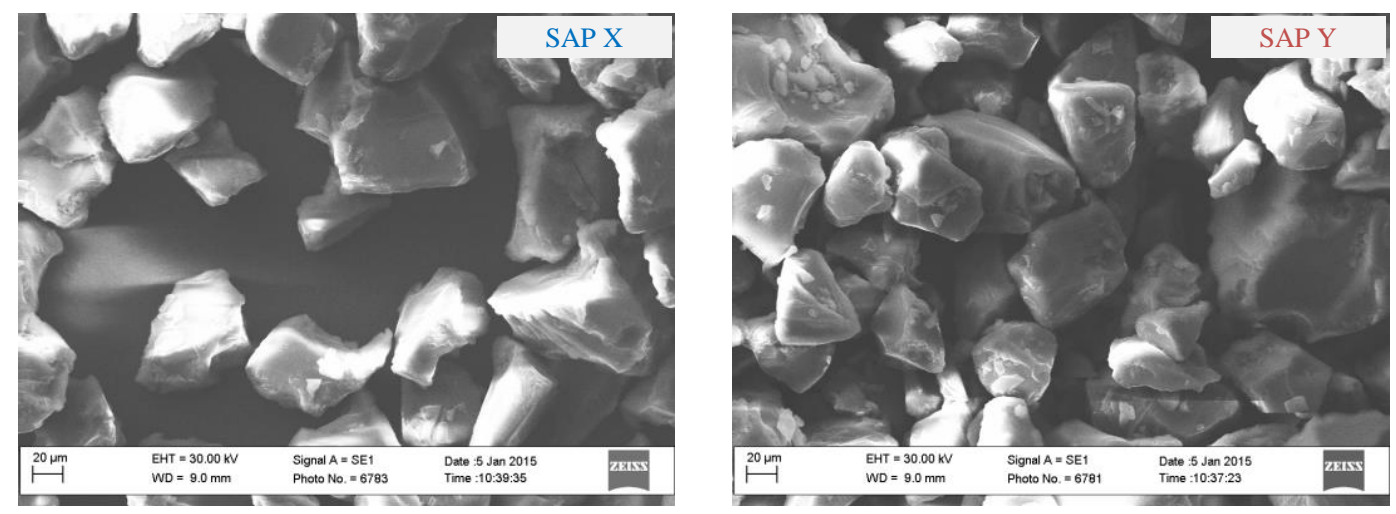

Fig. 3. SEM micrographs of SAP X and SAP Y, respectively.

Mortars have been prepared in the proportion of 1:2 (binder: sand) and with water/binder ratio (w/b) of 0.5 . This w/b ratio was obtained from the additional amount of water for the SAP with the highest WAC and applied for all mortar samples. Thus, it was assumed that all mortars have an effective w/b ratio greater (or equal to) 0.42 , and PC hydration would not be interrupted by lack of water in any time $[41,42]$. Similar w/b values were used by other authors $[33,44]$. Fine sand used as fine aggregate contained at least $90 \%$ of particles sizes below $0.425 \mathrm{~mm}$ [45]. Table 2 shows 
nomenclature of mortar samples, considering type of SAP and binder content used in this experimental programme.

Table 2 - Nomenclature of mortars samples.

\begin{tabular}{|c|c|c|c|}
\hline $\begin{array}{c}\text { Sample } \\
\text { nomenclature }\end{array}$ & $\begin{array}{l}\text { Type of } \\
\text { SAP }\end{array}$ & $\begin{array}{c}\text { CEM I } \\
{[\%]}\end{array}$ & $\begin{array}{c}\text { GGBS } \\
{[\%]}\end{array}$ \\
\hline R0 & \multirow{4}{*}{ - } & 100 & 0 \\
\hline $\mathrm{R} 25$ & & 75 & 25 \\
\hline R50 & & 50 & 50 \\
\hline $\mathrm{R} 75$ & & 25 & 75 \\
\hline $\mathrm{X} 0$ & \multirow{4}{*}{ SAP X } & 100 & 0 \\
\hline $\mathrm{X} 25$ & & 75 & 25 \\
\hline $\mathrm{X} 50$ & & 50 & 50 \\
\hline $\mathrm{X} 75$ & & 25 & 75 \\
\hline $\mathrm{Y0}$ & \multirow{4}{*}{ SAP Y } & 100 & 0 \\
\hline Y25 & & 75 & 25 \\
\hline Y50 & & 50 & 50 \\
\hline Y75 & & 25 & 75 \\
\hline
\end{tabular}

Autogenous shrinkage was tested by the sealed corrugated tubes method [46] (average of three specimens for each mortar) from the final setting time to 90 days, using a digital bench dilatometer. In order to identify the autogenous shrinkage tendency, representative and characteristics points were plotted and smoothly connected. Microstructural features and mechanical properties were evaluated after unsealed curing in climate chamber $\left(\mathrm{T}=21 \pm 2{ }^{\circ} \mathrm{C}\right.$ and $\left.\mathrm{RH}=40 \pm 5 \%\right)$ at $7,14,28$ and 90 days. Microstructural characteristics were analysed in terms of total porosity (\%) and pore size distribution (nm) using Mercury Intrusion Porosimetry (MIP) technique. Scanning Electron Microscopy (SEM) was used to characterize typical macro pores. Their diameter sizes were measured by Image-J software. Mechanical properties were verified by standard compressive strength determination method from prismatic specimens $\left(160 \times 40 \times 40 \mathrm{~mm}^{3}\right)$ [47]; averages of six samples for each mortar were considered.

\section{Results and discussions}

\subsection{Autogenous shrinkage}

Fig. 4 shows results of autogenous shrinkage measurements. Overall, SAPs reduced autogenous shrinkage in mortars with and without GGBS compared to the reference samples.

Mortars without SAP had the greatest values of autogenous shrinkage, clearly influenced by GGBS level: the greater GGBS content the greater was autogenous shrinkage. For all reference samples, shrinkage sharply increased in the first weeks and reduced its rate from the middle of the second month (considering sealed specimens of corrugated tubes). At 90 days, autogenous shrinkage reached approximate values of $-450,-600,-750$ and $-900 \mu \mathrm{m} / \mathrm{m}$ for mortars with $0 \%$, $25 \%, 50 \%$ and $75 \%$ of GGBS respectively.

Although relatively high w/b ratio $(0.50)$ has been adopted in this study, significant autogenous shrinkage for the reference mortars was observed. Generally, systems with w/b ratio up to 0.42 are expected to shrink due to self-desiccation processes [41,42]. However, it depends not only on the amount of water but also on the characteristics of cement, especially chemical composition and fineness $[48,49]$. Autogenous shrinkage greatly depends on the contents and degree of hydration of $\mathrm{C}_{3} \mathrm{~A}$ and $\mathrm{C}_{4} \mathrm{AF}$. Also, the finer the cement particle, the greater is autogenous shrinkage; the cement fineness induces a finer porous network and hence more intense capillary effects [50,51]. Other studies has found similar autogenous shrinkage values for the reference samples with $0.5 \mathrm{w} / \mathrm{b}$ ratio [14,51]. 

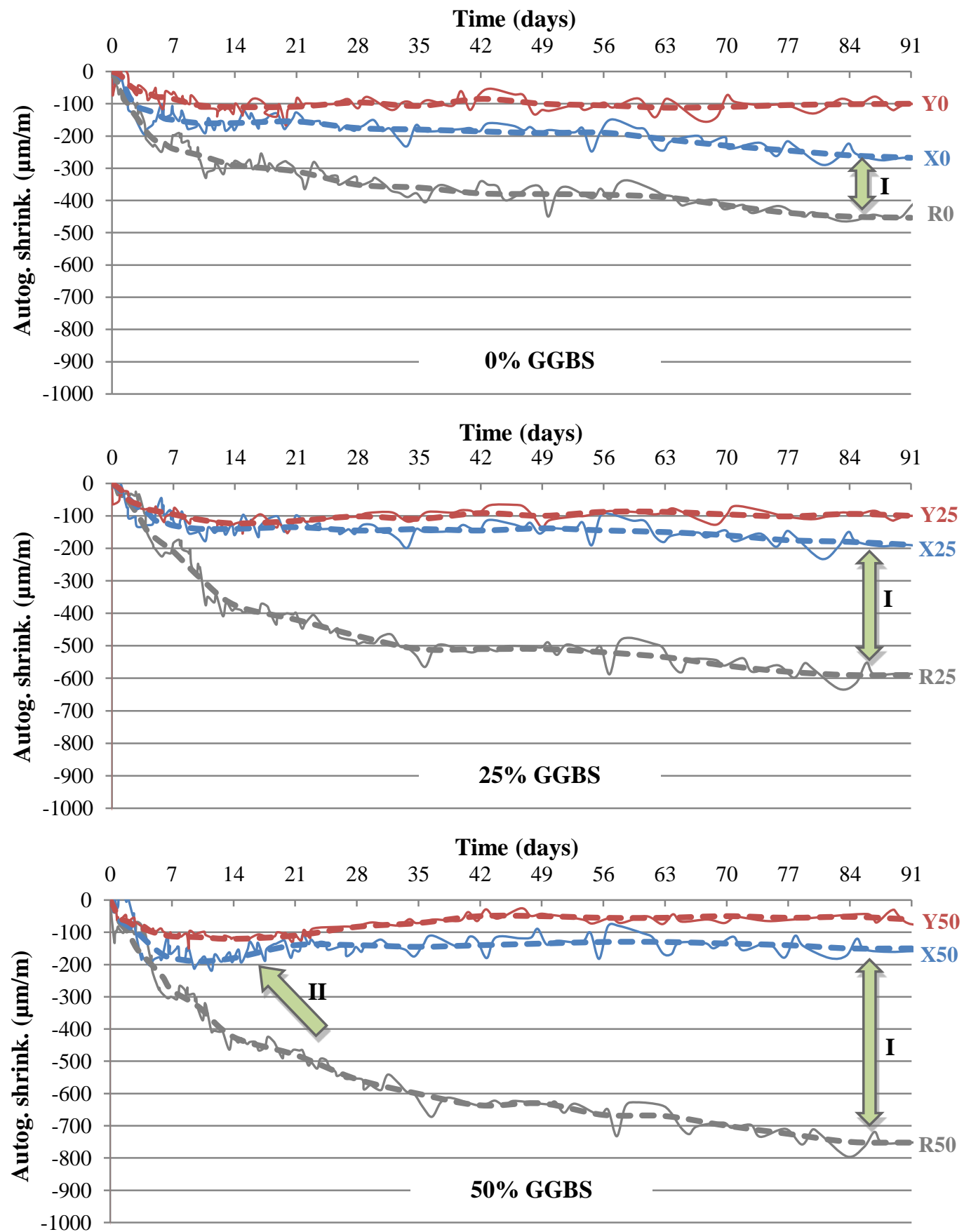

Time (days)

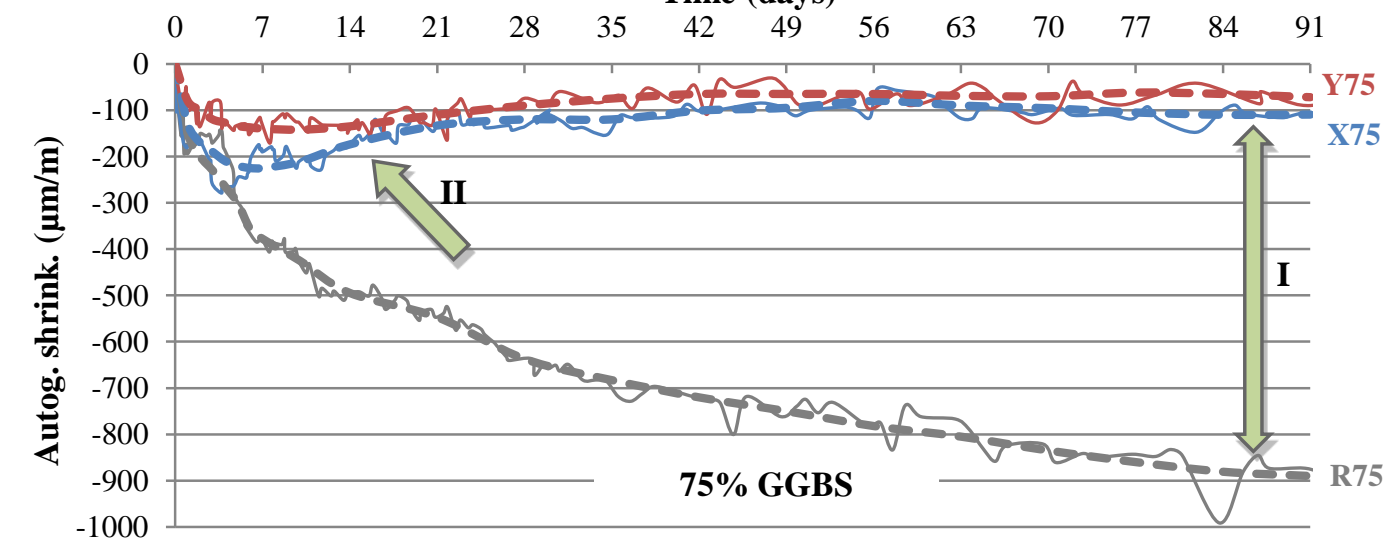

Fig. 4. Autogenous shrinkage development during 90 days (traced lines show autogenous shrinkage tendency). Arrows indicate relevant effects of SAP on PC-GGBS mortars. 
Moreover, when GGBS is added to the mix, autogenous shrinkage is considerably increased. The higher GGBS content the greater is autogenous shrinkage, as reported in the other studies [2,1418]. This result can be attributed to the physical presence of GGBS, the so-called filler effect. First, the substitution of PC by GGBS at the same w/b ratio indicates a dilution effect. The higher GGBS proportion the lower is the amount of clinker grains. Since GGBS has lower rate of reaction, there is relatively more space for formation of the clinker hydrates at early ages. Therefore, the degree of reaction of clinker component is significantly higher than in GGBS-free material. Additionally, GGBS surfaces may act as nucleation sites for hydrates [2,11]. However, this effect is relatively minor in the present study since PC particles are finer than GGBS ones (Fig. 2). Moreover, addition of GGBS may lead to formation of finer pores, which in turn results in increased autogenous shrinkage. The smaller capillaries the higher is tensile stress triggered by water menisci between pores' walls [14]. Thus, the increment of GGBS content can lead to formation of material, which is more prone to deformation.

Addition of SAPs significantly reduced autogenous shrinkage in all mortars when compared to the reference samples. The effectiveness of SAP as an internal curing agent has been proved for plain PC materials [21-27]. SAP Y seemed to be more efficient in reduction of autogenous shrinkage that may be attributed to its higher water absorption capacity. Thus, more water is available in the system that is gradually released. As a result, mortars with SAP Y had the lowest values of shrinkage in comparison with the other samples.

Moreover, GGBS level has influenced the behaviour over time and the final performance of mortars with SAP at 90 days. Firstly, the higher GGBS content the more pronounced was reduction in autogenous shrinkage by SAP, as indicated by Arrows I in Fig. 4. Secondly, for low or no GGBS content, mortars with SAP shrank in the first days (although less than the reference samples) and then either stabilized (for SAP Y) or followed in the same pace than the reference sample (for SAP $\mathrm{X}$ ). However, a slight swelling was noticed in SAP modified mortars with higher GGBS contents (above 50\%) after a maximum shrinkage around -200 and $-100 \mu \mathrm{m} / \mathrm{m}$ for SAP X and Y, respectively (Arrows II, Fig. 4). At 75\% of GGBS, specimens with both SAPs seem to reach similar values of shrinkage (below $-100 \mu \mathrm{m} / \mathrm{m}$ ) at later ages. This effect of "relative" expansion (after the maximum shrinkage is reached) seems to be more pronounced for SAP X specimens (with lower water absorption capacity). Other studies have confirmed an expansion in systems when using shrinkage reducing admixtures [35,52].

Overall, mortars with SAPs and high GGBS content shrank until the second week and, after that, they started to slightly swell. This effect may be related to the beginning of GGBS hydration facilitated by the presence of SAP as water supplier in certain range of pores (as further discussed). GGBS has reacted with water and the formation of hydrated products led to the "relative" expansion of SAP mortars. When water was consumed and SAP collapsed, no significant external volume changes were noticed, and autogenous shrinkage curves had a tendency to flatten out.

Moreover, GGBS reaction is directly related to the saturation of portlandite obtained from PC hydration. According to Fig. 1 [1], most of $\mathrm{CH}$ is formed during the first 1000h hydration (or 42 days), approximately when mortars with high GGBS contents exhibited maximum relative expansion. The maximum amount of portlandite means the max activation obtained for GGBS hydration, inducing the production of further $\mathrm{CSH}$ (Eq. 3). The more $\mathrm{CH}$, the higher is $\mathrm{pH}$ in the vicinity of GGBS grains, and hence the higher is the reactivity of slag. These later hydrated products fill extra spaces which were not filled by the cement hydrates due to the lack of clinker [2,53]. $\mathrm{CH}$ grains may also contribute to mortar expansion [52], but in a relatively minor manner. This is because in plain PC mortars, no further expansion was observed (Fig. 4). Additionally, although the amount of portlandite in PC-GGBS systems is similar or even higher than in CEM I mortars during the first days (due to this faster clinker reaction caused by filler effect), in long term the amount of $\mathrm{CH}$ is generally reduced [3,54,55].

On the other hand, no further swelling was observed in mortars without SAP in later ages. It can indicate that there is no sufficient amount of water (present in a specific range of pores, as further discussed) for late reaction of GGBS. In this case, GGBS can act as fine aggregate (finer than fine 
sand used) responsible for creation of large amount of finer pores (filler effect). Indeed, its double role as mineral admixture and very fine aggregate can also be noticed when analysing workability [36]; GGBS demands more water during mix preparation (for the same consistency) due to its higher capacity for absorption and adsorption compared with both cement and sand. Consequently, it increases porosity of mortars when compared to samples without GGBS. Results of microstructural analysis are discussed in Item 3.2.

\subsection{Microstructural characteristics}

GGBS addition can lead to higher total porosity due to reduction of cement content and decrease of the total volume of hydrates formed [3]. In general, the higher GGBS content the higher is total porosity (overall tendency in Fig 5). As the reaction of slag does not lead to such high increases in solid volume as does the reaction of clinker, total porosity in GGBS systems is expected to be higher than in plain PC mix [20].

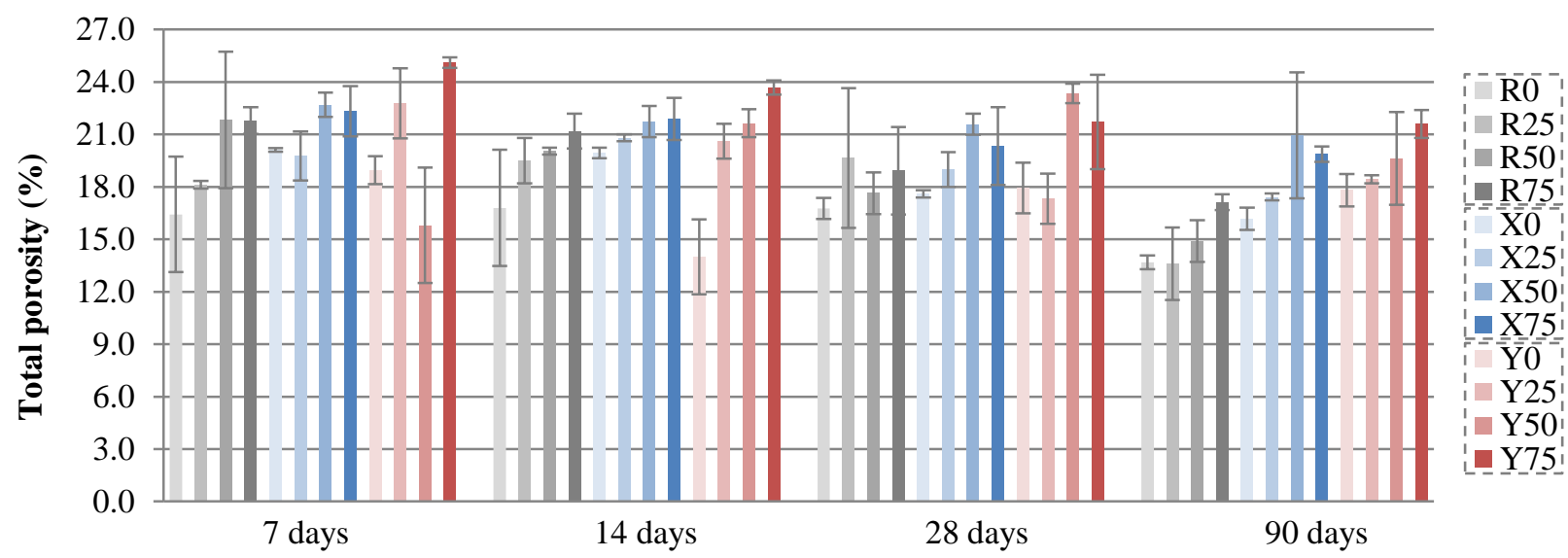

Fig. 5. Results of total porosity by MIP.

During the first 90 days, a general tendency of increased total porosity by SAP was noted. It was particularly evident when compared to the reference samples at 90 days. The highest total porosity values were mainly observed for the polymer with higher WAC; SAP Y was able to absorb more water from fresh mix and form larger capillary pores when it collapsed. The increment in porosity by SAP is aligned with other studies [29,44,56-58]. In an ordinary blended system (without SAP), the degree of GGBS reaction could be limited by the amount of space available to accommodate hydrated products. It seems that reaction of slag could even supress the reaction of the clinker phases due to a competition for space [2,20]. In this context, collapsed SAPs could further help GGBS products by providing, not only water, but also enough room for later CSH being deposited.

Moreover, GGBS addition altered mortars microstructure and changed pore size distribution patterns. Fig. 6 shows the comparison of pore size distribution curves for samples without and with $75 \%$ GGBS at the ages of 7, 14, 28 and 90 days. 

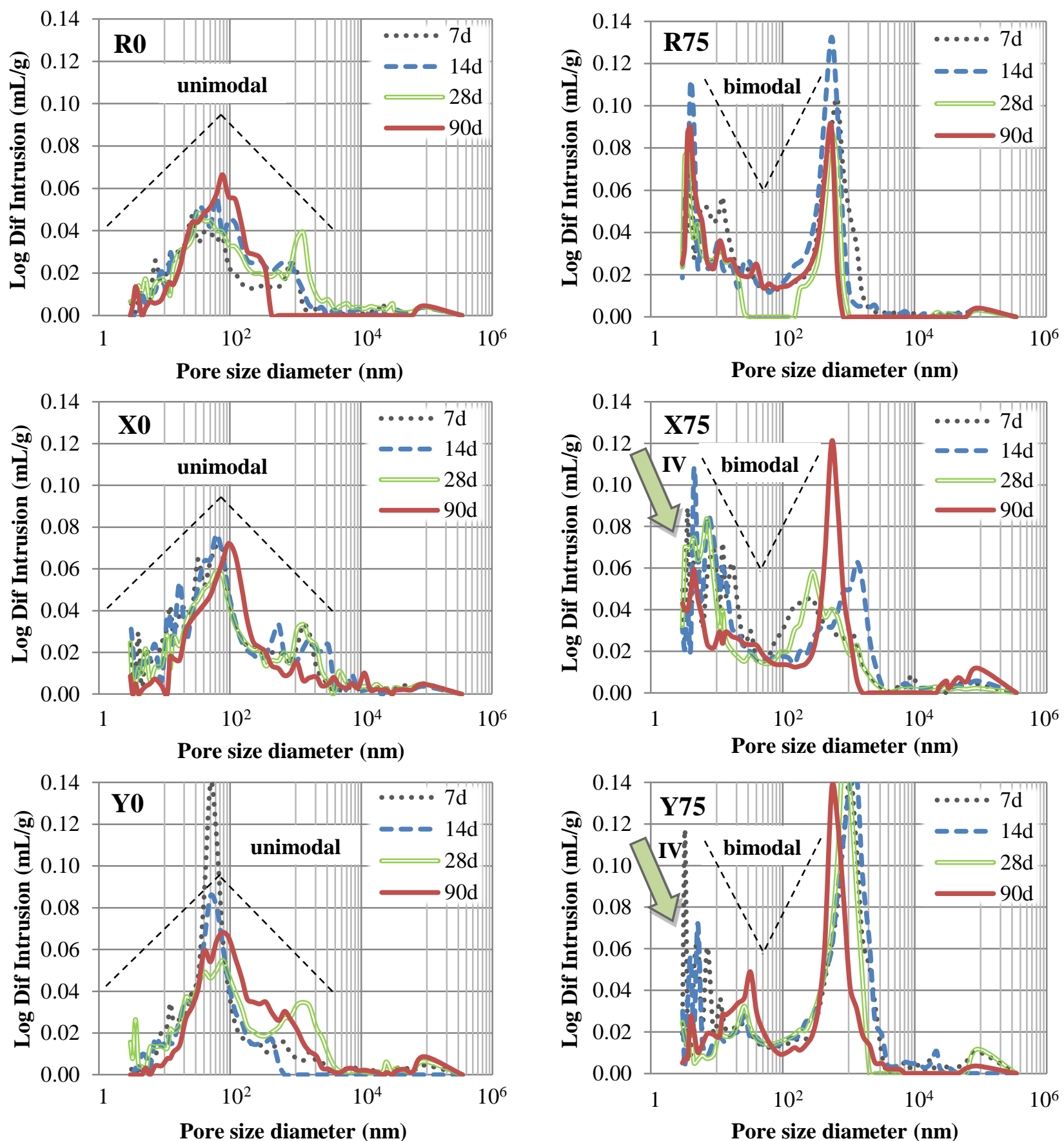

Fig. 6. Unimodal and bimodal distribution for samples with $0 \%$ and $75 \%$ of GGBS, respectively.

Pore size distribution curves for mortars with no or lower amount of GGBS are of unimodal shapes, with diameter range between 5-500 nm (peak around $80 \mathrm{~nm}$ ). However, as GGBS content was increased, bimodal curves started to dominate. In particular for high GGBS content, two predominant bands were formed: one with larger pores $(200-700 \mathrm{~nm})$ and the other with smaller pores (below $50 \mathrm{~nm}$ ). Firstly, the presence of larger particles of GGBS when compared to CEM I (Fig. 2) could form the band with peak around $400 \mathrm{~nm}$. These larger particles could be responsible for reduction of GGBS reactivity and hence for an increase of mortars porosity. Also, GGBS can decrease total volume of hydrates formed in a blended system, increasing its porosity [3]. Secondly, GGBS can produce finer capillaries due to its filler effect [2,14]; its particles are smaller than fine sand. Also, the greater water demand in fresh mix [36] can indicate that GGBS grains absorb/adsorb more water than other dry materials. The availability of more water attached to GGBS particles could promote creation of denser network of $\mathrm{CSH}$, with the predominance of pores under $50 \mathrm{~nm}$ of 
diameter. The results showed that both models (unimodal curves for $0 \%$ of GGBS and bimodal curves for mortars with $75 \%$ of GGBS) have the same pattern for all samples studied.

This GGBS capacity to produce finer pores can directly contribute to autogenous shrinkage development (Fig. 4). In smaller capillaries, the force of attraction between pore walls due to water surface tension is increased. Thus, higher tensile stress in the capillary pores (for mortars with GGBS) can result in an increased autogenous shrinkage [14].

SAPs can also modify pore size distribution in PC-GGBS mortars, as shown in Fig. 7.
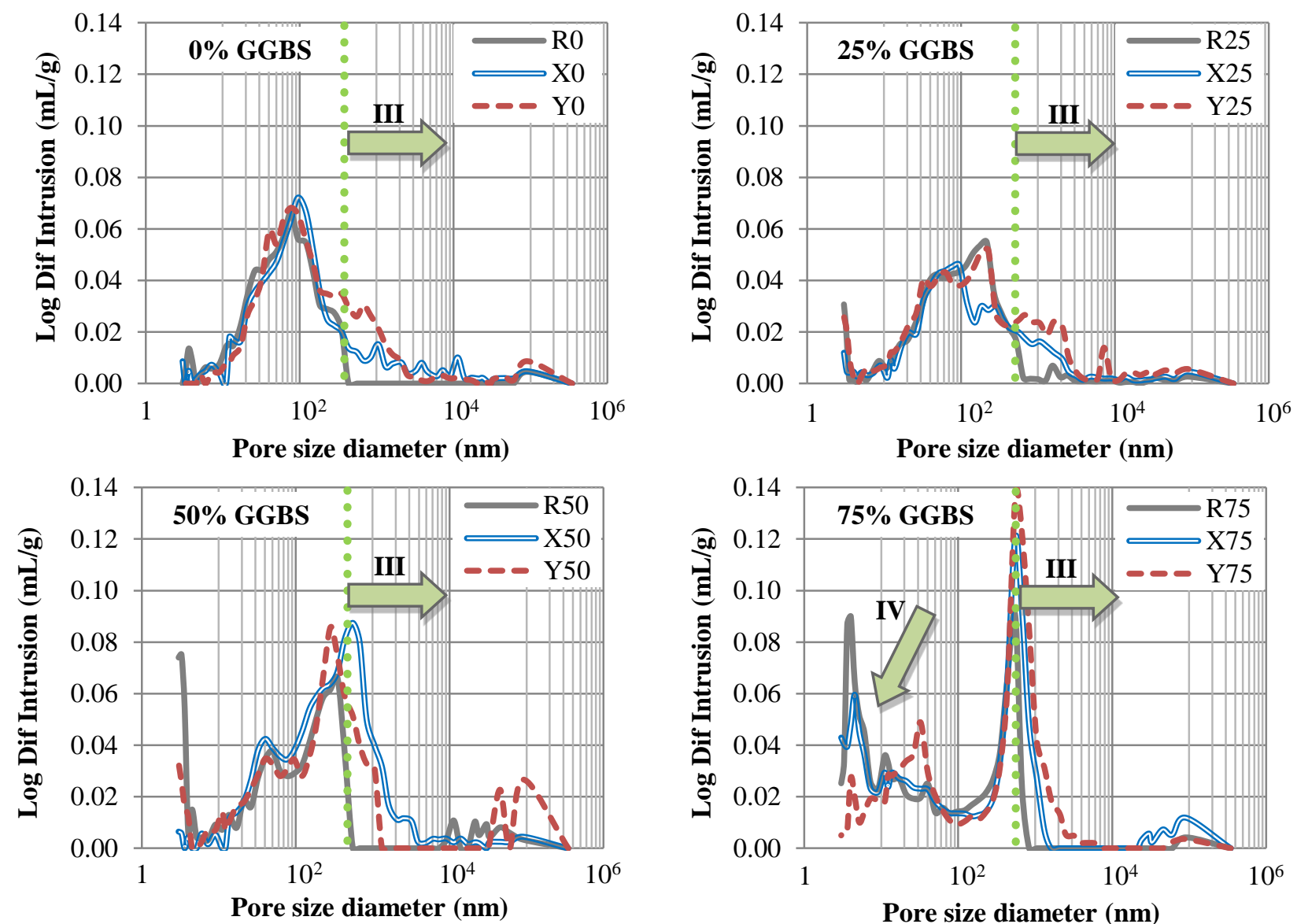

Fig. 7. Pore size distribution curves of mortars at 90 days. Arrows indicate relevant effects of SAP on PCGGBS mortars porosity.

Overall, SAPs had a tendency to form larger capillary pores when compared to the reference samples. Arrows III (Fig. 7) indicate that pores with diameter greater than $500 \mathrm{~nm}$ may be formed by collapsing SAPs. In general, mortars with SAP Y created the largest pores; SAP Y absorbs more water from fresh mix, and consequently leaves behind larger voids in hardened state. This formation of larger capillaries resulted in higher total porosity of SAP Y specimens at 90 days when compared to the other samples (Fig. 5).

Formation of larger voids by SAPs can also have an impact on the surface roughness as seen on SEM micrographs (Fig. 8). Macro pores and big concaves can be clearly identified in SAP samples. The higher total porosity resulting from macro pore formation in SAP containing specimens, regardless the amount of water in the mix, have been previously reported [33,44,58]. In particular, Snoeck et al. [44] found that the diameter size of macro pores was in the range of $270 \pm 54 \mu \mathrm{m}$ for PC mortars using SAPs with similar particle sizes and WAC. These values are in the same order as those showed in Fig. 8, for typical macro pores in SAP mortars at 90 days. 

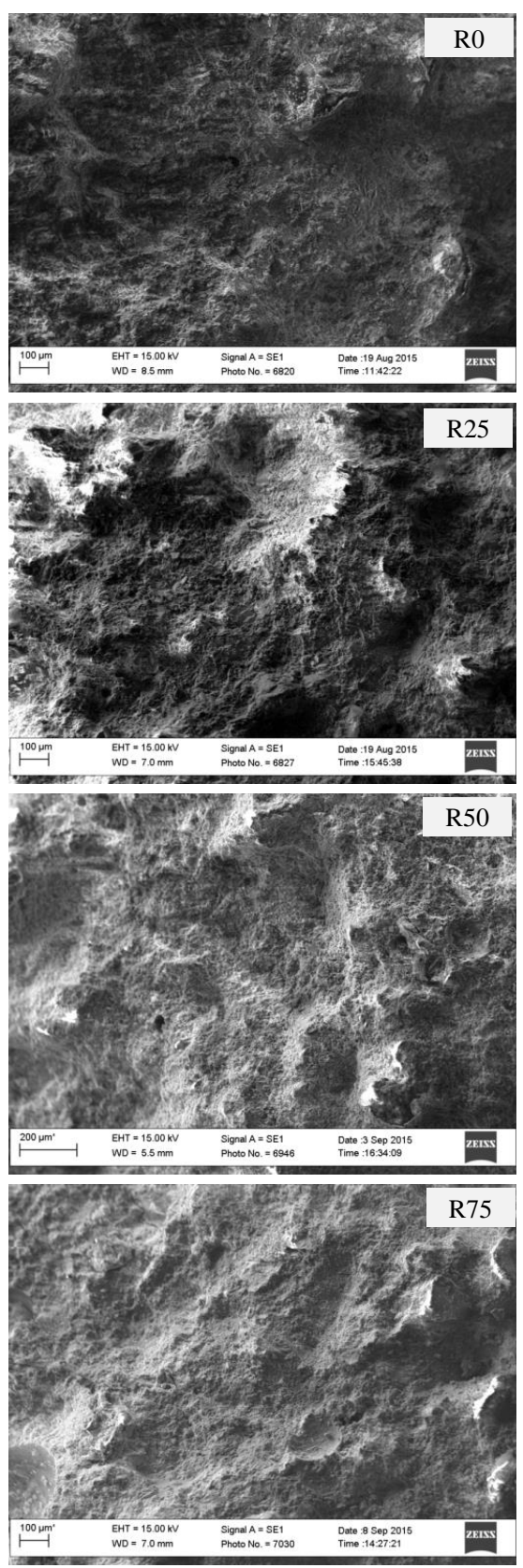
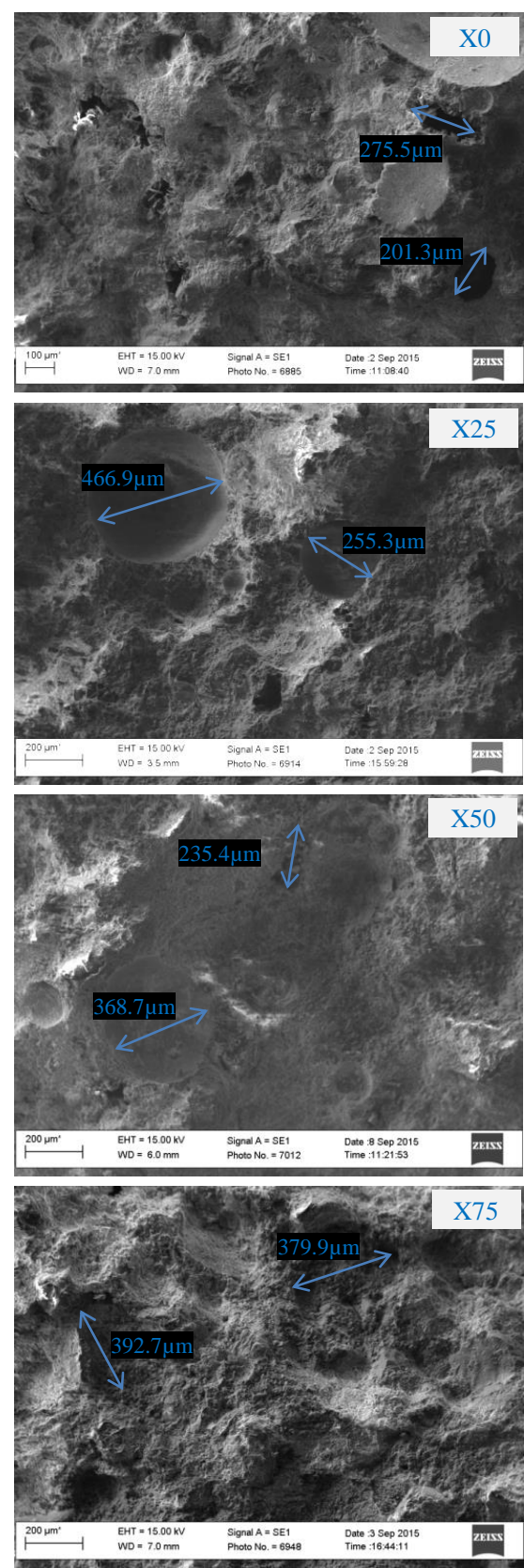
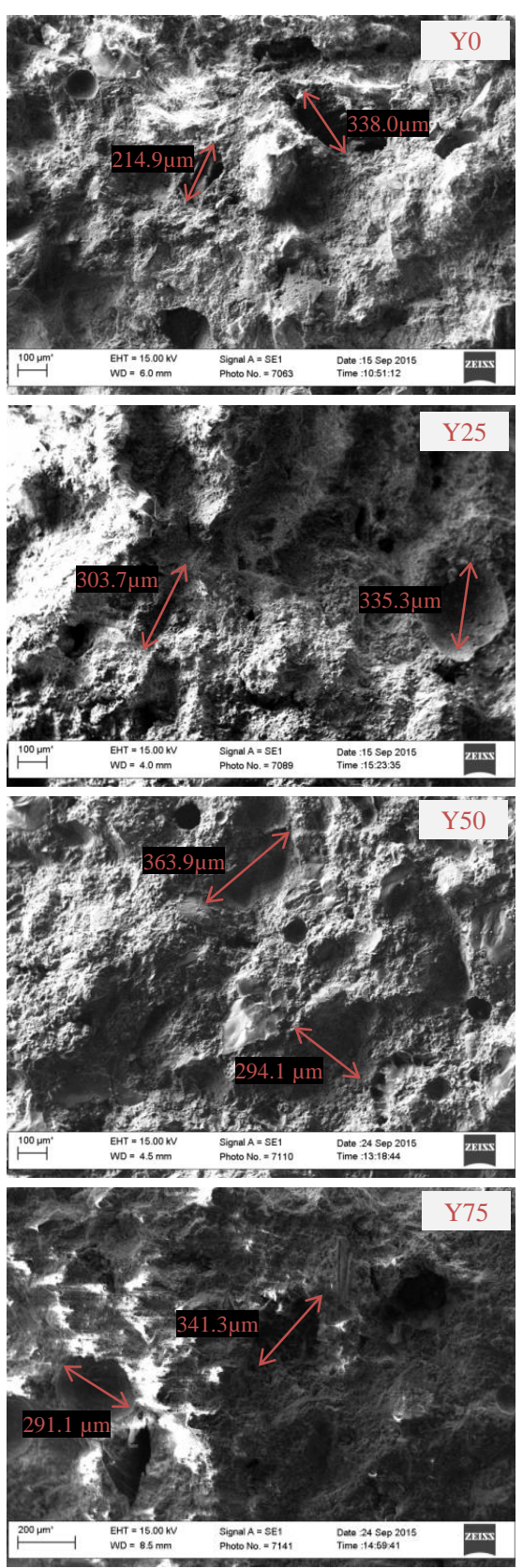

Fig. 8. SEM micrographs of mortars at 90 days. Higher roughness surface can be observed in samples modified by SAPs when compared to the reference samples. Typical macro pores are indicated on SAP samples.

Besides producing larger pores, SAPs can also have an effect on smaller pores in mortars with high GGBS content; decreased amount of pores with diameter under $20 \mathrm{~nm}$ (indicated by Arrow IV, Fig. 6-7). This reduction can be attributed to the filling of pores with later GGBS hydration products that were facilitated by SAP's water supply. Desorption of SAP is mainly controlled by osmotic pressure in early-ages. After that, there is a detachment between SAP and the pore wall (from the cement matrix). Thus, SAP remaining moisture can be released to the paste under humidity gradient (in form of vapour) for continuous curing in later stages [59]. The water stored by polymer tends to move through smaller pores since they provide more surface area for water to adhere to [60]. Indeed, there is a preference of GGBS products in precipitating into smaller pores in non-saturatedwater condition [61,62]. In this context, SAP Y is more efficient to provide additional water for hydration and hence the observed reduction of small pores in high GGBS mortars. On the other hand, no significant reduction was recorded for the reference sample since there was not enough water for further GGBS hydration. 
As smaller pores are being filled with later hydration products, these products start to exert pressure upon the pore walls. Due to the potential lack of room for CSH precipitation, there is a "space competition" between hydrated products and hardened microstructure. Consequently, this stress leads to the "relative" expansion of the hardened bulk volume in later ages as indicated by Arrows II (Fig. 4).

This outcome is in line with findings of Scrivener, Juilland \& Monteiro [2]. The authors acknowledge that, despite of the lack of long-term data on GGBS hydration processes, the amount of space available may be a critical factor. Berodier \& Scrivener [20] concluded that slag reaction is limited at higher replacement levels due to the lack of space in systems with w/b ratios of 0.6 and 0.4 . The authors showed that capillary pore space is refined in long term and is soon dominated by pores with sizes approximately between $8-16 \mathrm{~nm}$. These values coincide with those found in the present paper, i.e. pores below $20 \mathrm{~nm}$. Below this diameter range, cementitious reactions (GGBS and clinker phase) are limited by the lack of water-filled capillary pores at later ages. Thus, it seems that there is a space competition for filling the smaller pores with further CSH in long term [2]. Therefore, a small relative "expansion" was recorded in SAP-PC-GGBS systems.

Indeed, the difference in increased mortar porosity by using different types of SAP has affected autogenous shrinkage development, especially for high GGBS content. Coming back to Fig. 4, it seems that the higher GGBS content the closer is $\mathrm{X}$ and $\mathrm{Y}$ curves. It can indicate that further external expansion is more pronounced in samples with SAP X. This is because the polymer with lower WAC creates less or smaller pores than SAP Y. Thus, any further formation of hydrated products (due to high content of GGBS) is more likely to provoke relative increase in bulk volume. On the other hand, mortars with SAP Y have higher porosity and hence they can provide more sites for nucleation of late hydration products. These products can also be deposited into the larger SAP Y capillary pores and consequently SAP Y mortars expand less than those with SAP X. In this way, although SAP Y increases porosity (produces larger pores when compared to the other samples), it more efficiently reduces autogenous shrinkage and supply more water and space for further GGBS hydration.

Therefore, mechanisms of hardening process in PC-GGBS mortars modified by SAP, during the first 90 days, may be affected by saturation of $\mathrm{CH}$, availability of SAP water and empty spaces for depositing hydrated products. Fig. 9 shows a schematic representation of the effect of nano pores filling on the bulk volume expansion.

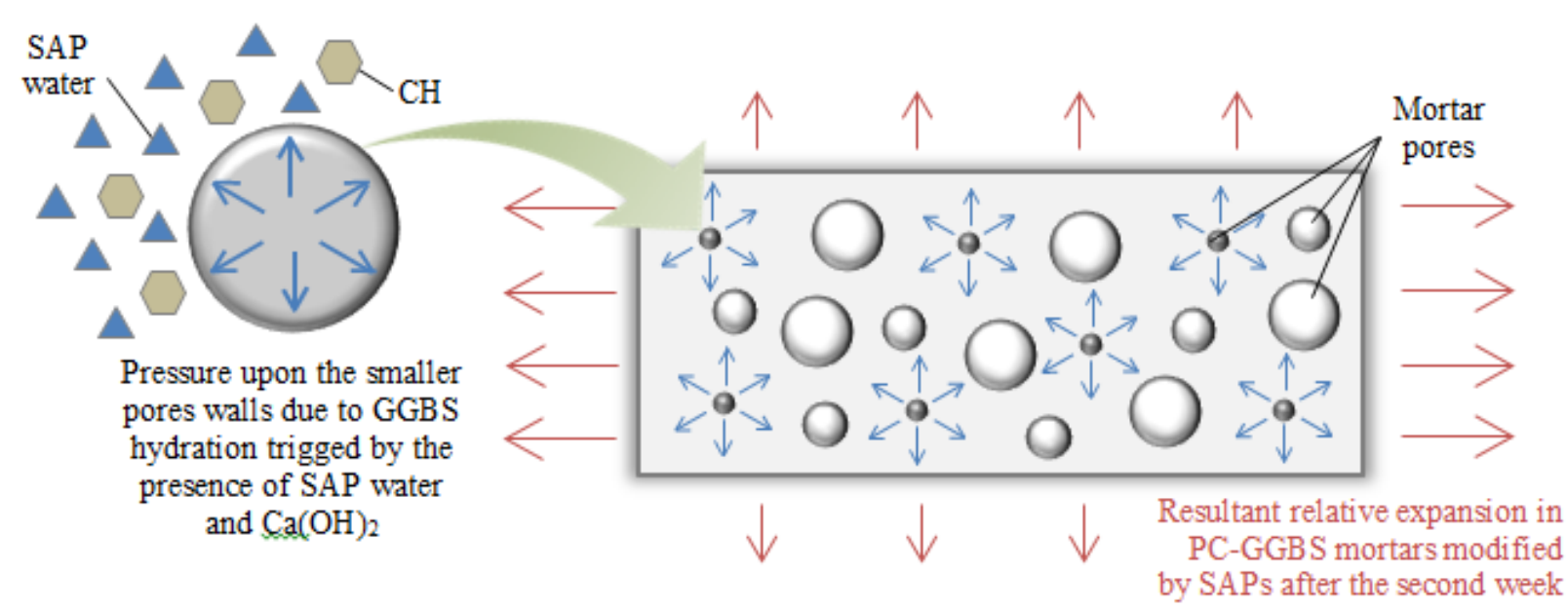

Fig. 9. GGBS hydration products deposited into smaller pores and its effect on bulk volume expansion.

Overall, SAP addition increases total porosity in PC-GGBS mortars due to its capacity to create macro pores and larger capillaries in collapsed state. On the other hand, SAP can aid GGBS hydration, contributing to water supply for further reactions in a prolonged time (up to 90 days). The later GGBS reaction is facilitated not only by SAP water (that is adhered to smaller pores, with high surface area) but also by the presence of portlandite from $\mathrm{PC}$ hydration (max $\mathrm{CH}$ saturation is 
about $42^{\text {nd }}$ day). Thus, the later hydration products start to form after the second week into the smaller pores (under than 20nm) resulting in an increment of internal compressive stress. This, in turn, leads to a slight "relative" expansion of the bulk volume of SAP mortars with high GGBS contents.

\subsection{Compressive strength}

Results of compressive strength are shown in Fig. 10. In general, the higher level of replacement by GGBS the lower compressive strength. This can be related to the higher porosity observed for GGBS mortars due to its lower hydration rate compared to CEM I [3]. It has been shown that $90 \%$ of slag has reacted after 3.5 year hydration [5].

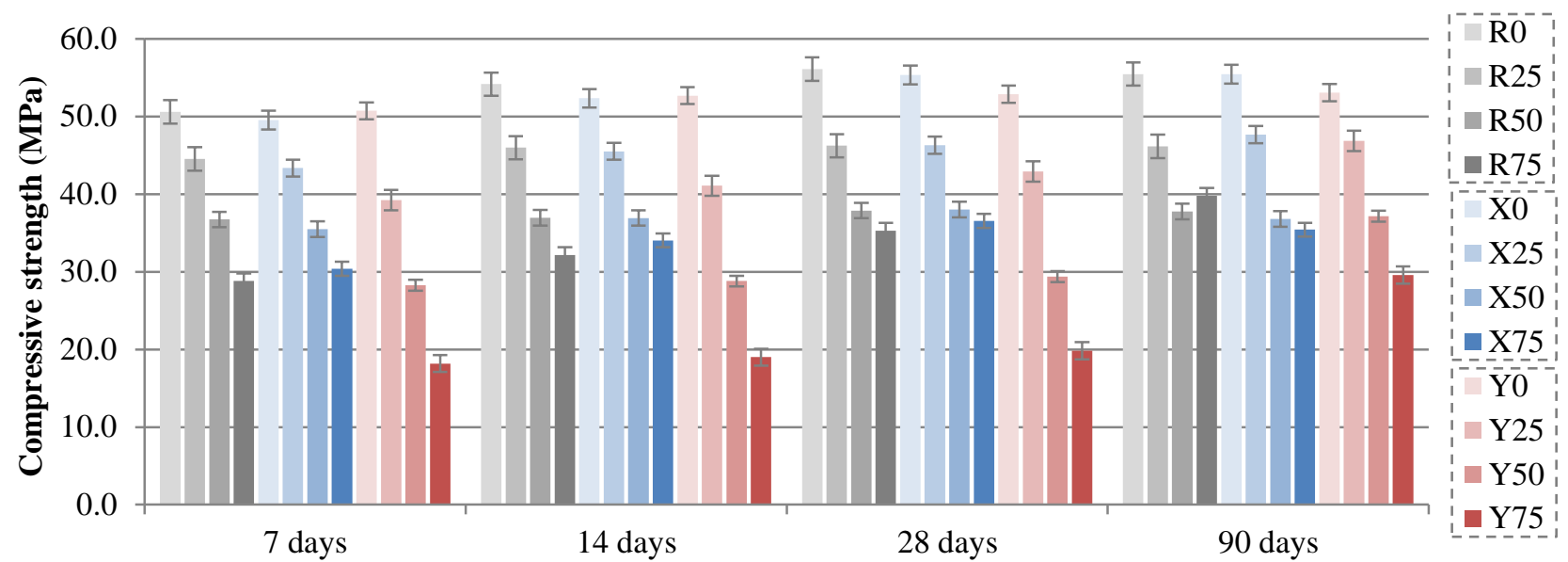

Fig. 10. Results of compressive strength.

Mortars with SAP X had a very similar performance to the reference samples. Apart from mortars with high GGBS content at 90 days, all the other samples had compressive strength values in the same order of those without polymer. It can indicate that the increment in porosity by addition of SAP X may not significantly interfere with compressive strength results, especially when lower GGBS levels are considered (up to 50\%).

Addition of SAP Y to the mix seemed to reduce compressive strength in the first month. However, mortars with this polymer presented comparable results to the reference samples with lower GGBS contents (up to 50\%) at 90 days. As SAP X samples, mortars with $75 \%$ of GGBS modified by SAP Y also had lower values of strength in comparison to the reference sample. When results were compared over the time, a considerable gain of strength can be noticed for samples with higher GGBS contents and the polymer with higher WAC (samples Y50 and Y75). Although SAP Y has reduced compressive strength because of increased porosity (compared to the reference), it improved the rate of GGBS hydration in later ages. It seemed that GGBS hydrated products may have filled pores formed by SAP Y and significantly increased compressive strength values at 90 days (compared to 28 days).

Overall, it seemed that SAP may not have significant effect on mechanical properties in advanced ages for lower GGBS contents, even with increased porosity in a unimodal pore size distribution. As GGBS level is increased and its pore size distribution is changed to bimodal curves, the increase in porosity by both SAP and GGBS can be evinced by reduction in strength level. In order to keep the same compressive strength values for mortars with and without SAP, the limit level of PC replacement by GGBS should be $50 \%$. Above this content, decrease in compressive strength takes place. 


\section{Conclusions}

From the experimental results, the following can be concluded:

- Mortars with SAP can significantly reduce autogenous shrinkage, especially with higher GGBS contents. After max shrinkage (up to $-200 \mu \mathrm{m} / \mathrm{m}$ ) in the first weeks, mortars with high GGBS level modified by SAPs slightly swell due to the filling of nano pores with later hydration slag products. Further CSH is formed due to the availability of water supplied by SAP and a presence of space created by collapsed SAPs. Also, GGBS reaction is activated by $\mathrm{CH}$ formed in $\mathrm{PC}$ hydration; the max relative expansion takes place at the end of week 6 , when the max amount of portlandite is formed;

- Both studied SAPs are able to supply water for longer GGBS hydration. Its products can be deposited into the smaller pores (under $20 \mathrm{~nm}$ of diameter) formed by high contents of GGBS. It is because smaller pores have greater water affinity due to their higher surface area. SAP Y is more efficient in decreasing the number of smaller pores due to its higher capacity to absorb and also to provide water for later hydration;

- Pores with diameter greater than $500 \mathrm{~nm}$ may be formed by addition of polymer. SAP Y, with higher water absorption capacity, is able to produce larger pores than SAP X. However, this increment of porosity by SAP does not affect compressive strength for low GGBS contents at 90 days (considering the same w/b ratio). Reduction in mechanical properties can be observed for substitution levels above $50 \%$ when compared to the reference samples;

- Overall, although SAP increases total porosity in PC-GGBS mortars, it reduces autogenous shrinkage, extends GGBS hydration, and keeps the same level of compressive strength (for low GGBS contents) when compared to the reference samples with the same w/b ratios.

\section{Acknowledgements}

The authors acknowledge National Council for Scientific and Technological Development (CNPq - Brazil) for the financial support, Hanson Cements for CEM I and GGBS supply, and BASF for SAPs supply.

\section{References}

[1] B. Lothenbach, F. Winnefeld, Thermodynamic modelling of the hydration of Portland cement, Cem. Concr. Res. 36 (2006) 209-226. doi:10.1016/j.cemconres.2005.03.001.

[2] K.L. Scrivener, P. Juilland, P.J.M. Monteiro, Advances in understanding hydration of Portland cement, Cem. Concr. Res. 78 (2015) 38-56. doi:10.1016/j.cemconres.2015.05.025.

[3] B. Lothenbach, K. Scrivener, R.D. Hooton, Supplementary cementitious materials, Cem. Concr. Res. 41 (2011) 1244-1256. doi:10.1016/j.cemconres.2010.12.001.

[4] A. Vollpracht, B. Lothenbach, R. Snellings, J. Haufe, The pore solution of blended cements: a review, Mater. Struct. 49 (2016) 3341-3367. doi:10.1617/s11527-015-0724-1.

[5] B. Lothenbach, G. Le Saout, M. Ben Haha, R. Figi, E. Wieland, Hydration of a low-alkali CEM III/B-SiO2 cement (LAC), Cem. Concr. Res. 42 (2012) 410-423. doi:10.1016/j.cemconres.2011.11.008.

[6] S. Kumar, R. Kumar, A. Bandopadhyay, T.C. Alex, B. Ravi Kumar, S.K. Das, S.P. Mehrotra, Mechanical activation of granulated blast furnace slag and its effect on the properties and structure of portland slag cement, Cem. Concr. Compos. 30 (2008) 679-685. doi:10.1016/j.cemconcomp.2008.05.005.

[7] O. Peyronnard, M. Benzaazoua, Estimation of the cementitious properties of various industrial by-products for applications requiring low mechanical strength, Resour. Conserv. Recycl. 56 (2011) 22-33. doi:10.1016/j.resconrec.2011.08.008. 
[8] A. Oner, S. Akyuz, An experimental study on optimum usage of GGBS for the compressive strength of concrete, Cem. Concr. Compos. 29 (2007) 505-514. doi:10.1016/j.cemconcomp.2007.01.001.

[9] M. Thomas, The effect of supplementary cementing materials on alkali-silica reaction: A review, Cem. Concr. Res. 41 (2011) 1224-1231. doi:10.1016/j.cemconres.2010.11.003.

[10] J.L. Provis, Geopolymers and other alkali activated materials: why, how, and what?, Mater. Struct. 47 (2014) 11-25. doi:10.1617/s11527-013-0211-5.

[11] K.L. Scrivener, B. Lothenbach, N. De Belie, E. Gruyaert, J. Skibsted, R. Snellings, A. Vollpracht, TC 238-SCM: hydration and microstructure of concrete with SCMs, Mater. Struct. 48 (2015) 835-862. doi:10.1617/s11527-015-0527-4.

[12] G.C. Cordeiro, R.D. Toledo Filho, L.M. Tavares, E.M.R. Fairbairn, Pozzolanic activity and filler effect of sugar cane bagasse ash in Portland cement and lime mortars, Cem. Concr. Compos. 30 (2008) 410-418. doi:10.1016/j.cemconcomp.2008.01.001.

[13] F.C.R. Almeida, A. Sales, J.P. Moretti, P.C.D. Mendes, Sugarcane bagasse ash sand (SBAS): Brazilian agroindustrial by-product for use in mortar, Constr. Build. Mater. 82 (2015) 31-38. doi:10.1016/j.conbuildmat.2015.02.039.

[14] M. Valcuende, F. Benito, C. Parra, I. Miñano, Shrinkage of self-compacting concrete made with blast furnace slag as fine aggregate, Constr. Build. Mater. 76 (2015) 1-9. doi:10.1016/j.conbuildmat.2014.11.029.

[15] W. Zhang, Y. Hama, S.H. Na, Drying shrinkage and microstructure characteristics of mortar incorporating ground granulated blast furnace slag and shrinkage reducing admixture, Constr. Build. Mater. 93 (2015) 267-277. doi:10.1016/j.conbuildmat.2015.05.103.

[16] C. Jiang, Y. Yang, Y. Wang, Y. Zhou, C. Ma, Autogenous shrinkage of high performance concrete containing mineral admixtures under different curing temperatures, Constr. Build. Mater. 61 (2014) 260-269. doi:10.1016/j.conbuildmat.2014.03.023.

[17] M. Bouasker, N.E.H. Khalifa, P. Mounanga, N. Ben Kahla, Early-age deformation and autogenous cracking risk of slag-limestone filler-cement blended binders, Constr. Build. Mater. 55 (2014) 158-167. doi:10.1016/j.conbuildmat.2014.01.037.

[18] K.M. Lee, H.K. Lee, S.H. Lee, G.Y. Kim, Autogenous shrinkage of concrete containing granulated blast-furnace slag, Cem. Concr. Res. 36 (2006) 1279-1285. doi:10.1016/j.cemconres.2006.01.005.

[19] A.C.A. Muller, K.L. Scrivener, A.M. Gajewicz, P.J. McDonald, Densification of C-S-H Measured by 1H NMR Relaxometry, J. Phys. Chem. C. 117 (2013) 403-412. doi:10.1021/jp3102964.

[20] E. Berodier, K. Scrivener, Evolution of pore structure in blended systems, Cem. Concr. Res. 73 (2015) 25-35. doi:10.1016/j.cemconres.2015.02.025.

[21] V. Mechtcherine, H.-W. Reinhardt, eds., Application of Superabsorbent Polymers ( SAP ) in Concrete Construction: State-of-the-Art Report Prepared by Technical Committee 225-SAP, Springer, RILEM, 2012. doi:10.1007/978-94-007-2733-5.

[22] V. Mechtcherine, M. Gorges, C. Schroefl, A. Assmann, W. Brameshuber, A.B. Ribeiro, D. Cusson, J. Custódio, E.F. Silva, K. Ichimiya, S. Igarashi, A. Klemm, K. Kovler, A.N. Mendonça Lopes, P. Lura, V.T. Nguyen, H.-W. Reinhardt, R.D.T. Filho, J. Weiss, M. Wyrzykowski, G. Ye, S. Zhutovsky, Effect of internal curing by using superabsorbent polymers (SAP) on autogenous shrinkage and other properties of a high-performance finegrained concrete: results of a RILEM round-robin test, Mater. Struct. 47 (2013) 541-562. doi:10.1617/s11527-013-0078-5. 
[23] B. Craeye, M. Geirnaert, G. De Schutter, Super absorbing polymers as an internal curing agent for mitigation of early-age cracking of high-performance concrete bridge decks, Constr. Build. Mater. 25 (2011) 1-13. doi:10.1016/j.conbuildmat.2010.06.063.

[24] M.T. Hasholt, O.M. Jensen, K. Kovler, S. Zhutovsky, Can superabsorent polymers mitigate autogenous shrinkage of internally cured concrete without compromising the strength?, Constr. Build. Mater. 31 (2012) 226-230. doi:10.1016/j.conbuildmat.2011.12.062.

[25] C. Schröfl, V. Mechtcherine, M. Gorges, Relation between the molecular structure and the efficiency of superabsorbent polymers (SAP) as concrete admixture to mitigate autogenous shrinkage, Cem. Concr. Res. 42 (2012) 865-873. doi:10.1016/j.cemconres.2012.03.011.

[26] D. Shen, X. Wang, D. Cheng, J. Zhang, G. Jiang, Effect of internal curing with super absorbent polymers on autogenous shrinkage of concrete at early age, Constr. Build. Mater. 106 (2016) 512-522. doi:10.1016/j.conbuildmat.2015.12.115.

[27] A.J. Klemm, F.C.R. Almeida, Application of Superabsorbent polymers as novel admixture for cementitious materials, Concr. Plant Int. J. (2016) 38-46.

[28] A.N.M. Lopes, E.F. Silva, D.C.C. Dal Molin, R.D. Toledo Filho, Shrinkage-reducing admixture: Effects on durability of high-strength concrete, ACI Mater. J. 110 (2013) 365374.

[29] A.J. Klemm, K.S. Sikora, The effect of Superabsorbent Polymers (SAP) on microstructure and mechanical properties of fly ash cementitious mortars, Constr. Build. Mater. 49 (2013) 134-143. doi:10.1016/j.conbuildmat.2013.07.039.

[30] H. Gonçalves, B. Gonçalves, L. Silva, N. Vieira, F. Raupp-Pereira, L. Senff, J.A. Labrincha, The influence of porogene additives on the properties of mortars used to control the ambient moisture, Energy Build. 74 (2014) 61-68. doi:10.1016/j.enbuild.2014.01.016.

[31] D. Snoeck, L.F. Velasco, A. Mignon, S. Van Vlierberghe, P. Dubruel, P. Lodewyckx, N. De Belie, The effects of superabsorbent polymers on the microstructure of cementitious materials studied by means of sorption experiments, Cem. Concr. Res. 77 (2015) 26-35. doi:10.1016/j.cemconres.2015.06.013.

[32] M.T. Hasholt, O.M. Jensen, Chloride migration in concrete with superabsorbent polymers, Cem. Concr. Compos. 55 (2015) 290-297. doi:10.1016/j.cemconcomp.2014.09.023.

[33] V. Mechtcherine, C. Schroefl, M. Wyrzykowski, M. Gorges, P. Lura, D. Cusson, J. Margeson, N. De Belie, D. Snoeck, K. Ichimiya, V. Falikman, S. Friedrich, Effect of superabsorbent polymers ( SAP ) on the freeze - thaw resistance of concrete : results of a RILEM interlaboratory study, Mater. Struct. 50 (2017). doi:10.1617/s11527-016-0868-7.

[34] H. Beushausen, M. Gillmer, M. Alexander, The influence of superabsorbent polymers on strength and durability properties of blended cement mortars, Cem. Concr. Compos. 52 (2014) 73-80. doi:10.1016/j.cemconcomp.2014.03.008.

[35] D. Snoeck, O.M. Jensen, N. De Belie, The influence of superabsorbent polymers on the autogenous shrinkage properties of cement pastes with supplementary cementitious materials, Cem. Concr. Res. 74 (2015) 59-67. doi:10.1016/j.cemconres.2015.03.020.

[36] F. do Couto Rosa Almeida, A.J. Klemm, Effect of Superabsorbent Polymers (SAP) on Fresh State Mortars with Ground Granulated Blast-Furnace Slag (GGBS), in: 5th Int. Conf. Durab. Concr. Struct., Shenzhen, 2016. doi:10.5703/1288284316136.

[37] C. Song, Y.C. Choi, S. Choi, Effect of internal curing by superabsorbent polymers - Internal relative humidity and autogenous shrinkage of alkali-activated slag mortars, Constr. Build. Mater. 123 (2016) 198-206. doi:10.1016/j.conbuildmat.2016.07.007.

[38] M. Wyrzykowski, P. Lura, Reduction of Autogenous Shrinkage in Opc and Bfsc, in: XIII Int. 
Conf. Durab. Build. Mater. Components - XIII DBMC, Sao Paulo, 2015: pp. 999-1005.

[39] BS-EN 197-1, Cement Part 1: Composition, Specifications and Conformity Criteria for Common Cements (2011).

[40] BS EN 15167-1, Ground granulated blast furnace slag for use in concrete, mortar and grout Part 1: Definitions, specifications and conformity criteria (2006).

[41] T. Powers, Absorption of Water by Portland Cement Paste during the Hardening Process, Ind. Eng. Chem. 27 (1935) 790-794. doi:10.1021/ie50307a011.

[42] O.M. Jensen, P.F. Hansen, Water-entrained cement-based materials: I. Principles and theoretical background, Cem. Concr. Res. 32 (2001) 973-978. doi:10.1016/S00088846(01)00463-X.

[43] EN 1015-3, Methods of Test for Mortar for Masonry - Part 3: Determination of consistence of fresh mortar (by flow table) (2006).

[44] D. Snoeck, D. Schaubroeck, P. Dubruel, N. De Belie, Effect of high amounts of superabsorbent polymers and additional water on the workability, microstructure and strength of mortars with a water-to-cement ratio of 0.50, Constr. Build. Mater. 72 (2014) 148-157. doi:10.1016/j.conbuildmat.2014.09.012.

[45] BS EN 13139, Aggregates for mortar (2013).

[46] ASTM-C1698-09, Standard Test Method for Autogenous Strain of Cement Paste and Mortars (2009).

[47] BS EN 1015-11, Methods of Test for Mortar for Masonry - Part 11: Determination of Flexural and Compressive Strength of Hardened Mortar (2006).

[48] A. Alrifai, S. Aggoun, E.-H. Kadri, G. De Schutter, A. Noumowe, Influence of aggregate skeleton on shrinkage properties: validation of the model developed by Le Roy for the case of self-compacting concrete, Mater. Struct. 44 (2011) 1593-1607. doi:10.1617/s11527-0119721-1.

[49] E. Tazawa, S. Miyazawa, Influence of cement and admixture on autogenous shrinkage of cement paste, Cem. Concr. Res. 25 (1995) 281-287. doi:10.1016/0008-8846(95)00010-0.

[50] P. Mounanga, M. Bouasker, A. Pertue, A. Perronnet, A. Khelidj, Early-age autogenous cracking of cementitious matrices: physico-chemical analysis and micro/macro investigations, Mater. Struct. 44 (2011) 749-772. doi:10.1617/s11527-010-9663-z.

[51] Z. Jiang, Z. Sun, P. Wang, Autogenous relative humidity change and autogenous shrinkage of high-performance cement pastes, Cem. Concr. Res. 35 (2005) 1539-1545. doi:10.1016/j.cemconres.2004.06.028.

[52] G. Sant, B. Lothenbach, P. Juilland, G. Le Saout, J. Weiss, K. Scrivener, The origin of early age expansions induced in cementitious materials containing shrinkage reducing admixtures, Cem. Concr. Res. 41 (2011) 218-229. doi:10.1016/j.cemconres.2010.12.004.

[53] A. Pourjavadi, S.M. Fakoorpoor, P. Hosseini, A. Khaloo, Interactions between superabsorbent polymers and cement-based composites incorporating colloidal silica nanoparticles, Cem. Concr. Compos. $37 \quad$ (2013) 196-204. doi:10.1016/j.cemconcomp.2012.10.005.

[54] I. Pane, W. Hansen, Investigation of blended cement hydration by isothermal calorimetry and thermal analysis, Cem. Concr. Res. 35 (2005) 1155-1164. doi:10.1016/j.cemconres.2004.10.027.

[55] J. Escalante, L.. Gómez, K. Johal, G. Mendoza, H. Mancha, J. Méndez, Reactivity of blastfurnace slag in Portland cement blends hydrated under different conditions, Cem. Concr. Res. 
31 (2001) 1403-1409. doi:10.1016/S0008-8846(01)00587-7.

[56] J. Justs, M. Wyrzykowski, D. Bajare, P. Lura, Internal curing by superabsorbent polymers in ultra-high performance concrete, Cem. Concr. Res. 76 (2015) 82-90. doi:10.1016/j.cemconres.2015.05.005.

[57] O.M. Jensen, P.F. Hansen, Water-entrained cement-based materials: II. Experimental observations, Cem. Concr. Res. 32 (2002) 973-978. doi:10.1016/S0008-8846(02)00737-8.

[58] S. Laustsen, M.T. Hasholt, O.M. Jensen, Void structure of concrete with superabsorbent polymers and its relation to frost resistance of concrete, Mater. Struct. 48 (2015) 357-368. doi:10.1617/s11527-013-0188-0.

[59] F. Wang, J. Yang, S. Hu, X. Li, H. Cheng, Influence of superabsorbent polymers on the surrounding cement paste, Cem. Concr. Res. 81 (2016) 112-121. doi:10.1016/j.cemconres.2015.12.004.

[60] D.E. Ramos, Walnut Production Manual, University of California, Division of Agriculture and Natural Resources, Communication Services-Publications, 1998.

[61] K. Li, Q. Zeng, M. Luo, X. Pang, Effect of self-desiccation on the pore structure of paste and mortar incorporating 70\% GGBS, Constr. Build. Mater. 51 (2014) 329-337. doi:10.1016/j.conbuildmat.2013.10.063.

[62] Y.C. Choi, J. Kim, S. Choi, Mercury intrusion porosimetry characterization of micropore structures of high-strength cement pastes incorporating high volume ground granulated blastfurnace slag, Constr. Build. Mater. 137 (2017) 96-103. doi:10.1016/j.conbuildmat.2017.01.076. 